\title{
PARÂMETROS GENÉTICOS DA RESISTÊNCIA DA SOJA AO NEMATÓIDE DE CISTO RAÇA $1\left(^{1}\right)$
}

\author{
MARA FERNANDES MOURA $\left({ }^{*}\right)$; ROLANDO VENCOVSKY $\left({ }^{4}\right)$; JOÃO FLÁVIO VELOSO SILVA $\left({ }^{5}\right)$; \\ LIZZ KEZZY DE MORAIS ( $\left.{ }^{3}\right)$; NARA FERNANDES MOURA $\left({ }^{2}\right)$; JOSÉ BALDIN PINHEIRO $\left({ }^{4}\right)$
}

\begin{abstract}
RESUMO
O trabalho objetivou verificar o comportamento de Linhagens Endogâmicas Recombinantes (RIL's - Recombinant Imbred Lines), obtidas do cruzamento entre Hartwig (genitor resistente) e EMGOPA316 (genitor suscetível) em relação à resistência ao nematóide de cisto da soja - NCS (raça 1) e a estimação de parâmetros genéticos e de progressos de seleção como implicação no melhoramento de plantas. Os parâmetros envolveram o índice de fêmeas (IF) obtido na avaliação de 176 linhagens $\mathrm{F}_{6}$ de soja quanto à resistência ao NCS. Avaliaram-se os genótipos quanto à resposta ao NCS em casa de vegetação e calcularam-se as médias dos IF dos genótipos avaliados. Posteriormente, foram realizadas a distribuição de freqüência e a análise de variância e, então, estimado o número de locos segregantes envolvidos na resistência das linhagens ao NCS (raça 1). Estimou-se o progresso de seleção $(i=-2,154)$ entre as linhagens avaliadas (com diferentes números de repetições), bem como a herdabilidade em nível de média $\left(h^{2}\right)$. Assim conclui-se que: a) A distribuição de normalidade das médias dos IF, bem como a estimativa da herdabilidade e a estimativa do número de locos segregantes indicam que a resposta das linhagens ao NCS (raça 1) tem caráter de herança poligênica; b) Foram encontradas linhagens promissoras para resistência ao NCS, porém, como este é de difícil avaliação recomenda-se utilizar maior número de linhagens $\mathrm{F}_{6}$ na avaliação fenotípica e maior número de repetições para avaliação da reação ao NCS; c) A necessidade de se fazer correção para efeitos macroambientais aumentou o erro das estimativas.
\end{abstract}

Palavras-chave: Heterodera glycines, resistência genética, Glycine max, ganho de seleção.

\section{ABSTRACT \\ GENETIC PARAMETERS FOR SOYBEAN RESISTANCE TO RACE 1 CYST NEMATODE}

This study aimed at verify the behavior of Recombinant Inbreed Lines, resulting of a cross between Hartwig (resistant parental) and EMGOPA-316 (susceptible parental) to NCS soybean nematode (race 1) and to estimate genetic parameters and those of selection progress. Estimated parameters used the mean female index (IF) obtained through the evaluation of $176 \mathrm{~F}_{6}$ lines for NCS resistance. The genotypes were evaluated in greenhouse. The frequency distribution and the variance analyses were performed to estimate the number of segregating loci involved in the resistance to NCS. The selection progress was estimated $(i=-2,154)$ among the lines evaluated using different numbers of repetitions, as well the herdability $\left(\mathrm{h}^{2}\right)$. It was concluded that: a) The normality distribution of the average IF, as well the estimated herdability and the number o segregation loci indicated the resistance to NCS (race 1) is poligenic; b) Promising NCS resistant lines were found. However, as the resistance test is difficult a larger number of $F_{6}$ lines and a larger number of repetitions should be evaluated; c) The necessity of correction due to macroenvironment effects increased the bias of the estimatives.

Key words: Heterodera glycines, genetic resistance, Glycine max, selection progress.

( $\left.{ }^{1}\right)$ Recebido para publicação em 19 de janeiro de 2007 e aceito em 12 de julho de 2007.

$\left({ }^{2}\right)$ Centro de Frutas, Instituto Agronômico, Caixa Postal 11, Jundiaí (SP). E-mail: mouram@iac.sp.gov.br (*) Autora correspondente.

$\left({ }^{3}\right)$ Centro de Grãos e Fibras, Instituto Agronômico, Caixa Postal 28, 13012-970 Campinas (SP). E-mail: lizz@iac.sp.gov.br

$\left({ }^{4}\right)$ Departamento de Genética, ESALQ/USP, Caixa Posta 9, 13418-900 Piracicaba (SP). E-mail: baldin@esalq.usp.br

$\left({ }^{5}\right)$ Embrapa Soja, Caixa Postal 231, 86001-970 Londrina (PR). E-mail: veloso@cnpms.embrapa.br 


\section{INTRODUÇÃO}

O nematóide de cisto da soja (Heterodera glycines Ichinohe, 1952) é um dos principais patógenos da cultura, causando grandes prejuízos, além de ser de fácil disseminação. Nos últimos anos, a soja tem sido objetivo de grandes esforços na área do melhoramento, sendo a resistência a doenças o objetivo prioritário. Segundo YORINORI et al. (1993), cerca de 35 patógenos atacam a soja no Brasil, sendo Heterodera glycines ou Nematóide de Cisto da Soja (NCS) um dos principais fatores que limitam a produção dessa cultura.

Segundo Wrather et al. (2001), o nematóide de cisto da soja ocasionou perdas de aproximadamente 8,9 milhões de toneladas em 1998 nos dez maiores países produtores de soja. No Brasil, desde a primeira ocorrência na safra 1991/92, já foram encontradas 11 raças, sendo as raças 1 e 3 as predominantes. Estimase que a área afetada com o nematóide seja superior a 2 milhões de hectares (EMBrapa, 2003).

Devido ao potencial de danos desse patógeno, torna-se fundamental o estabelecimento de estratégias de manejo. Dentre estas, enquadram-se o estudo e a incorporação de alelos de resistência nas cultivares comerciais, pelos programas de melhoramento (Pí́POLO e Ferraz, 1999). Segundo Alzate-Marin et al. (2005) a utilização de cultivares resistentes ao NCS constituise uma das formas mais práticas, eficientes e úteis de controle do NCS.

Embora os estudos de genética clássica tenham tido sucesso na identificação de fontes de resistência ao NCS, foram pouco esclarecedores a respeito da base genética da resistência. As dificuldades verificadas no estudo da herança podem ser atribuídas, em parte, ao alto nível de variabilidade do patógeno em campo e, ainda, devido ao método utilizado para classificar as plantas como resistentes ou suscetíveis (ARANTES et al., 1999).

Os estudos realizados através da genética clássica e molecular têm mostrado que sua herança é governada por poucos genes (três a quatro em média) sendo, portanto, preponderantemente oligogênica. A existência de ligação gênica (cluster de genes) e de alelismo múltiplo não podem ser descartados (RAOArelli, 1994; Concibido et al. 1997) Dessa forma, fica claro a necessidade de se estudar melhor a base genética da herança da resistência da soja ao nematóide de cisto.

O objetivo deste trabalho foi verificar o comportamento de Linhagens Endogâmicas Recombinantes (RIL's - Recombinant Inbred Lines), obtidas do cruzamento entre Hartwig (genitor resistente) e EMGOPA-316 (genitor suscetível) em relação ao nematóide de cisto da soja (raça 1) e a estimação de parâmetros genéticos e do progresso na seleção, os quais têm implicações importantes em programas de melhoramento genético.

\section{MATERIAL E MÉTODOS}

Utilizaram-se 176 linhagens $\mathrm{F}_{6}$ de soja, obtidas a partir do cruzamento entre as cultivares Hartwig e EMGOPA-316, sendo a primeira resistente ao nematóide de cisto da soja (NCS) e a segunda suscetível, porém adaptada ao Estado de Goiás.

$O$ avanço das gerações foi realizado na Universidade Federal de Goiás, pelo método SPD (Single Pod Descent) sendo utilizadas de duas a três sementes provenientes de uma única vagem para semeadura. Inicialmente foram conduzidas 834 plantas $F_{2}$ para o avanço de gerações até $F_{6}$. As sementes $\mathrm{F}_{2}$, bem como as das gerações seguintes, foram semeadas em campo. Os genótipos foram cultivados utilizando-se o espaçamento de $0,45 \mathrm{~m}$ entre linhas e $0,50 \mathrm{~m}$ entre plantas. O número de indivíduos por geração foi mantido constante. A geração $\mathrm{F}_{3}$ foi semeada em 31/10/2001, a $\mathrm{F}_{4}$ em $1 . \%$ $3 / 2002$ e a $\mathrm{F}_{5}$ em 25/2/2003.

As sementes da geração $\mathrm{F}_{6}$ foram levadas para a Embrapa Soja, em Londrina (PR), onde foram semeadas e submetidas à inoculação com o NCS - raça 1, a fim de se avaliar a resistência desses genótipos. Porém, utilizaram-se apenas 176 genótipos, amostrados ao acaso, visto que era restrita a possibilidade de inoculação e avaliação da resistência ao nematóide em casa de vegetação.

Os genótipos foram semeados em copos plásticos preenchidos com areia. Após o início da germinação, aproximadamente de três dias, as plântulas foram transplantadas para vasos de argila com volume aproximado de 1 litro e com uma mistura de areia ( 3 partes) e de terra ( 1 parte), previamente esterilizadas. No momento do transplante foi efetuada a inoculação das plântulas com a suspensão de ovos e juvenis do NCS (raça 1). Cada vaso recebeu aproximadamente um volume de 1,6 mL, contendo aproximadamente 4.000 ovos e juvenis de segundo estádio. A suspensão foi aplicada próxima ao colo das plântulas, seguida de irrigação leve, com o objetivo de evitar o ressecamento dos ovos do nematóide.

Os vasos foram mantidos em condições de casa de vegetação, com o objetivo de minimizar variações ambientais, tais como temperatura e umidade, e dispostos segundo o delineamento inteiramente casualizado, com três repetições. Também 
foram submetidas à inoculação dez plantas de cada genitor (resistente e suscetível) e dos genótipos diferenciadores, os quais foram intercalados com a finalidade de aferir a efetividade e precisão da inoculação realizada com o nematóide. Os genótipos diferenciadores foram as cultivares Hartwig, Pickett, Lee, Peking e as PIs 88788, 437654, 90763.

Após 35 dias da inoculação, realizou-se a contagem do número de fêmeas e cistos, em cada sistema radicular das plantas, obtendo-se o número de fêmeas (NF) e o índice de fêmeas (IF), obtido pela razão entre o número de fêmeas ou cistos no genótipo avaliado e o padrão de suscetibilidade (cultivar Lee), multiplicada por 100 (SCHIMITT e SHANNON, 1992). Uma vez obtido este índice, as linhagens foram classificadas em quatro classes, a saber: resistente (IF de $0,0 \%$ a $10,0 \%$ ), moderadamente resistente (IF de $11 \%$ a $30 \%$ ), moderadamente suscetível (IF de $31 \%$ a $60 \%$ ) e suscetível (IF > 60\%).

Inicialmente, foram realizados os testes de normalidade para os dados referentes às médias do índice de fêmeas dos 176 genótipos avaliados e a análise de variância dos dados relativos a esta variável. Em seguida, os dados experimentais foram utilizados para estimar os parâmetros genéticos relativos ao IF do nematóide de cisto (raça 1). Foram estimados o número de locos segregantes $(\mathrm{Ng})$, a variância genética entre as linhagens $\mathrm{F}_{6} \mathrm{e}$ a herdabilidade em nível de média $\left(\mathrm{h}^{2}\right)$. Também foram realizadas as estimativas do ganho de seleção com diferentes números de repetições.

A estimativa do número de locos segregantes foi realizada através da expressão dada por Cockerham (1986), ou seja,

$$
N_{g}=\frac{D^{2}-C}{8 \sigma_{g}^{2}}=\frac{D^{2}-C}{4 \sigma_{g}^{21}}
$$

sendo:

$D$ : é a diferença fenotípica entre as médias dos genitores homozigóticos;

$C$ : é a correção para efeitos microambientais, já que $D$ é fenotípico;

$\sigma_{g}^{2}$ : é a variância genética aditiva da população $\mathrm{F}_{2}$ derivada dos genitores homozigóticos;

$\sigma_{g}^{2 \prime}$ : é a respectiva variância genética entre as linhagens $\mathrm{F}_{6}$.

A equivalência $8 \sigma_{g}^{2}=4 \sigma_{g}^{2 \prime}$ ou $2 \sigma_{g}^{2}=\sigma_{g}^{2 \prime}$ decorre do fato de se ter entre as linhagens $\mathrm{F}_{6}$ o dobro da variância genética aditiva da geração $\mathrm{F}_{2}$. Em termos gerais, essa variância aditiva entre linhagens de autofecundação com grau $\mathrm{F}$ de endogamia, é $\sigma_{g}^{2 \prime}=(1+F) \sigma_{g}^{2}$. No caso, tratando-se de linhagens $\mathrm{F}_{6}$ admitiu-se que $F \approx 1$.
Com os dados da análise da variância do ensaio, obteve-se a estimativa da variância genética entres as linhagens $\mathrm{F}_{6}$ como segue:

$$
\hat{\sigma}_{g}^{21}=\frac{Q M_{(\text {Linhagens })}-\mathrm{QM}_{(\text {Residuo })}}{r}
$$

sendo $Q M$ : o símbolo designando o quadrado médio e $r$ o número de repetições do ensaio. Esta última estimativa, juntamente com a estimativa da variância residual, permitiu estimar o progresso esperado $\left(G_{s}\right)$ de uma seleção entre as linhagens $F_{6}$, empregando-se a expressão:

$$
G_{s}=i \frac{\sigma_{g}^{2{ }^{\prime}}}{\sqrt{\sigma_{g}^{2{ }^{2}}+\sigma_{e}^{2} / r}}
$$

que é válida quando os dados obedecerem uma distribuição normal. A intensidade de seleção $i$, que é o diferencial de seleção estandardizado, dado em tabelas, foi tomado com sinal negativo, já que a seleção, no caso, visa reduzir a magnitude do caráter (mais resistência ao nematóide). A expressão (3) também foi utilizada para verificar quanto se incrementaria o progresso ao se usar quatro $(r=4)$ ou mais repetições, ao invés das três utilizadas. Essa operação foi feita a título de informação adicional aos melhoristas.

O coeficiente de herdabilidade, em nível de médias de linhagens foi estimado pela expressão:

$$
h_{m}^{2}=\frac{\sigma_{g}^{2,}}{\sigma_{g}^{2 \prime}+\frac{\sigma_{e}^{2}}{r}}
$$

As quantidades $D$ e $C$ da expressão (1) foram estimadas de modo que levasse em conta os efeitos ambientais prevalecentes.

Conforme já mencionado, o contraste $D$ é a diferença entre as médias do caráter nos genitores, ou seja, genericamente $D=\bar{P}_{1}-\bar{P}_{2}$. Na presente pesquisa, estimativas com boa precisão dessas médias foram obtidas em ambientes diferentes. Isso requereu correção para esses efeitos macroambientais, o que foi conseguido através de testemunha avaliada nas duas condições. Considere-se a seguinte notação:

$\bar{P}_{11}, \bar{P}_{12}$ : média do índice de fêmeas para Hartwig nos ambientes 1 e 2 respectivamente.

$\bar{P}_{21}, \bar{P}_{22}$ : média do índice de fêmeas para a EMGOPA-316 nos ambientes 1 e 2 respectivamente.

$\bar{T}_{1}, \bar{T}_{2}$ : média do índice de fêmeas da testemunha (PI88788) nos ambientes 1 e 2 respectivamente.

O contraste necessário é $D=\bar{P}_{11}-\hat{P}_{21}$, visto que não se dispunha de estimativa confiável e adequada da média $P_{21}$. Esta então foi estimada por:

$$
\hat{\bar{P}}_{21}=\bar{P}_{22}-\left(T_{2}-T_{1}\right) \text { sendo o contraste } \bar{T}_{2}-T_{1} \text { estimador }
$$
do efeito macroambiental entre os ambientes $1 \mathrm{e} 2$. 
Dessa maneira, obteve-se $\hat{D}=\bar{P}_{11}-\hat{P}_{21}$ como estimativa não viesada de $D$.

O genótipo PI88788 foi utilizado como testemunha, pois esteve presente nas duas avaliações, além de ser um genótipo difereciador que é suscetível à raça 1 do NCS.

Conforme recomendado por COCKERHAM (1986) fez-se também correção microambiental da estimativa $\hat{D}$. Esta corresponde à variância devida ao erro experimental desse contraste $\{V(\hat{D})=C\}$ que no caso é:

$$
C=Q M_{(\text {Re sidual })}\left(\left(\frac{1}{r_{11}}+\frac{1}{r_{22}}+\frac{1}{r_{a}}+\frac{1}{r_{b}}\right)\right)
$$

em que:

$r_{11}$ : é o número de repetições do genitor resistente avaliado no ambiente 1 ;

$r_{12}$ : número de repetições do genitor suscetível avaliado no ambiente 2 .

$r_{a}$ e $r_{b}$ : número de repetições da testemunha PI88788 avaliada nos ambientes 1 e 2 respectivamente.

$Q M_{(\text {Residual })}:$ quadrado médio do resíduo do experimento conduzido no ambiente 1 .

Desse modo, obteve-se a estimativa de $N_{g}$ por

$$
\hat{N}_{g}=\frac{(\hat{D})^{2}-\mathrm{C}}{4 \hat{\sigma}_{g}^{2 \prime}}
$$

\section{RESULTADOS E DISCUSSÃO}

A classificação dos genótipos quanto à resistência ao NCS (raça 1) pode ser mais bem visualizada na tabela 1 . Dentre os 176 genótipos avaliados, apenas sete $(3,98 \%)$ foram classificados como moderadamente resistentes, enquanto 53 genótipos $(30,11 \%)$ foram classificados como moderadamente suscetíveis e 116 genótipos $(65,91 \%)$ como suscetíveis. Esses dados revelam o predomínio de genótipos suscetíveis em relação às demais categorias, o que pode ser associado ao número de indivíduos avaliados (176); essa amostra pode ter sido insuficiente para a obtenção de maior número de indivíduos que reunissem os alelos de resistência. Deve-se considerar que a fenotipagem dos indivíduos é bastante trabalhosa e complicada quando se trata de um número grande de genótipos.

Noel (1992); Arantes et al. (1999); Carvalho et al. (1999); Concibido et al. (2004) relatam que esse tipo de avaliação geralmente é bastante demorado, demandando grande volume de recursos, espaço e mão-de-obra, principalmente quando se trata de programas de melhoramento em que o número de linhagens a serem testadas é bastante elevado. Ainda, constatou-se que na referida metodologia disponível para essa avaliação existe uma variação grande dentro das repetições, em um mesmo genótipo, quanto à resposta ao patógeno. Esse fato pode ser observado em determinado genótipo em que na primeira repetição ocorreram 78 cistos, na segunda, zero e na terceira, 27.

Tabela 1. Classificação dos 176 genótipos de soja quanto à reação ao ataque de nematóide de cisto da soja (raça 1)

\begin{tabular}{lcc}
\hline \multirow{2}{*}{ Nível de resistência } & \multicolumn{2}{c}{ Genótipos } \\
\cline { 2 - 3 } & $\mathrm{N}^{\mathrm{o}}$ & 0 \\
Resistente & 0 & 3,98 \\
Moderadamente resistente & 7 & 30,11 \\
Moderadamente suscetível & 53 & 65,91 \\
Suscetível & 116 & 100 \\
Total & 176 &
\end{tabular}

Neste trabalho, observou-se que a avaliação foi complexa em função de condições ambientais, do comportamento do patógeno e do hospedeiro e da interação entre os três fatores. Contudo, no universo avaliado, em função da complexidade da metodologia de avaliação, sete genótipos foram considerados promissores para a característica de resistência ao NCS (raça 1). Sugerem-se novas avaliações dos 176 genótipos para a confirmação do comportamento em relação à resistência ao NCS (raça 1), bem como dos genótipos que não foram avaliados, visto que o aumento do número de plantas da população para nova avaliação aumenta a oportunidade de encontrar genótipos resistentes.

Os testes de normalidade para os dados referentes às médias do índice de fêmeas dos 176 genótipos avaliados são mostrados na tabela 2. Não foi realizada a transformação dos dados para a análise. YuE et al. (2001b) mencionam que alguns estudos têm sugerido a não-transformação dos dados fenotípicos para análise de QTL, uma vez que a distribuição fenotípica dos dados transformados pode desviar da distribuição normal, ao contrário do que ocorre quando os dados não são transformados.

A partir dos resultados apresentados na tabela 2 , constatou-se a normalidade dos dados referentes à média do índice de fêmeas. Pôde-se observar também que houve certo número de genótipos com médias transgressivas para o índice de fêmeas, ou seja, médias mais altas do que o genitor suscetível (média $=105,4$ ) (Tabela 4). Também foi verificado que as médias das linhagens avaliadas não conseguiram alcançar a média do genitor resistente $(0,6)$. A variação 
transgressiva também foi observada em trabalho realizado por YUE et al. (2001a) em famílias $\mathrm{F}_{2: 3}$, derivadas do cruzamento entre a PI89772 (genitor resistente) e a cultivar Hamilton (genitor suscetível), inoculadas e avaliadas com a raça 5 do NCS.

Tabela 2. Resultados dos testes de normalidade obtidos a partir do caráter índice de fêmeas nas raízes dos genótipos avaliados

\begin{tabular}{lcc}
\hline Teste & Estatística & P-Valor \\
\hline Shapiro-Wilk & 0,991132 & 0,3497 \\
Kolmogorov-Smirnov & 0,048839 & 0,1500 \\
Cramer-von Mises & 0,053855 & 0,2500 \\
Anderson-Darling & 0,417649 & 0,2500 \\
\hline
\end{tabular}

Em estudo desenvolvido por Yue et al (2001b), em que se investigou a herança da resistência às raças 1, 2, 3, 5 e 14 ao NCS na PI438489B utilizando famílias $\mathrm{F}_{2: 3}$, os autores verificaram significância para as distribuições normais para as respostas às raças 1,2 e 14 do NCS. Também constataram variação transgressiva dentro das cinco populações estudadas. A hipótese da variação transgressiva é que os genitores não representam os possíveis extremos dos genótipos combinados. Dessa forma, pode ocorrer de os extremos excederem os valores dos genitores, se o genitor resistente não incluir todos os alelos possíveis para resistência (cultivar resistente com genes que conferem suscetibilidade à raça em questão), bem como o genitor suscetível não possuir todos os genes associados à suscetibilidade. Assim, um indivíduo novo pode, através da recombinação, apresentar maior suscetibilidade ou resistência que os pais.

Na tabela 3, é apresentado o resumo da análise de variância para o caráter índice de fêmeas, realizada a partir dos dados obtidos com avaliação dos genótipos. Verificou-se diferença significativa em nível de $1 \%$ de probabilidade, constatando-se que os genótipos possuem comportamentos diferenciados em relação à resistência ao nematóide de cisto (raça 1). Além disso, observou-se alto coeficiente de variação experimental, o que pode ser explicado pela complexidade de avaliação do NCS. Além disso, a avaliação inclui fases como semeadura, inoculação, contagem de fêmeas nas raízes, o que aumenta a possibilidade de imprecisão experimental.

As médias dos genitores e das linhagens $\mathrm{F}_{6}$ relativas ao índice de fêmeas, bem como as estimativas da herdabilidade ao nível de média e a variância genética entre as linhagens $F_{6}$ são apresentadas na tabela 4 .
Tabela 3. Análise de variância para o caráter índice de fêmeas nos genótipos avaliados para resistência ao nematóide de cisto (raça 1 )

\begin{tabular}{lcccc}
\hline FV & GL & SQ & QM & F \\
\hline Genótipos & 175 & 217180,7605 & 1241,0329 & $1,35^{* *}$ \\
Erro & 350 & 322148,2788 & 920,4237 & - \\
Total & 525 & 539329,0393 & - & - \\
$\bar{x}(\mathrm{IF})$ & 68,23 & - & - & - \\
CV $(\%)$ & 44,46 & - & - & \\
\hline
\end{tabular}

Tabela 4. Médias do índice de fêmeas para os genitores e linhagens $\mathrm{F}_{6}$, inoculadas com a raça 1 do NCS, estimativas da herdabilidade ao nível de média $\left(h^{2}\right)$, da variância genética entre as linhagens $F_{6}\left(\sigma_{g}^{2 \prime}\right)$ e do número de locos segregantes

\begin{tabular}{lcccc}
\hline \multirow{2}{*}{ Genótipos } & \multicolumn{4}{c}{ NCS (raça 1) } \\
\cline { 2 - 5 } & $\bar{x}$ & $h^{2}$ & $\sigma_{g}^{21}$ & $N_{g}$ \\
\hline Hartwig & 0,6 & & & \\
EMGOPA -316 & 105,4 & & & \\
Linhagens $\mathrm{F}_{6}$ & 68,2 & 0,258 & 107,28 & 23,77 \\
\hline
\end{tabular}

A estimativa da média relativa ao índice de fêmeas do genitor suscetível (EMGOPA-316) foi obtida a partir do fator de correção macroambiental $(124,1)$ e é mostrada na tabela 4 , juntamente com a média do genitor resistente (Hartwig).

Para se obter o fator de correção macroambiental foram necessárias as médias do índice de fêmeas obtidas para o genitor suscetível (ambientes 1 e 2) e das testemunhas (ambientes 1 e 2), as quais são apresentadas na Tabela 5.

Tabela 5. Médias do índice de fêmeas do NCS (raça 1) obtidas para o genitor suscetível e as testemunhas nos ambientes 1 e 2

\begin{tabular}{lcc}
\hline \multirow{2}{*}{ Genótipo } & \multicolumn{2}{c}{$\begin{array}{c}\text { Médias do índice } \\
\text { de fêmeas do NCS (raça 1) }\end{array}$} \\
\cline { 2 - 3 } Testemunha - PI 88788 & Ambiente 1 & Ambiente 2 \\
EMGOPA-316 & 53,4 & 177,5 \\
\hline
\end{tabular}

A correção microambiental da estimativa da diferença fenotípica entre as médias dos genitores homozigóticos, recomendada por COCKERHAM (1986), também foi realizada $(C=821,74)$. Assim, estimadas as correções macro e microambientais, obteve-se a estimativa do número de locos segregantes para o caráter avaliado $\left(N_{g}=23,77\right)$. 
As estimativas do ganho de seleção em que se simularam diferentes números de repetições $(=3,4$, $5,6,7,8,9$ e 10) foram obtidas para título de informação adicional aos melhoristas de soja. Considerou-se a intensidade de seleção de $4 \%$, correspondendo a um diferencial de seleção estandardizado $i=-2,154$. Essa intensidade de seleção foi considerada uma vez que foram selecionadas sete linhagens promissoras para o caráter resistência ao NCS (raça 1), o que corresponde a aproximadamente $4 \%$ das linhagens avaliadas. Os valores do ganho de seleção e os respectivos números de repetições utilizados para suas estimativas são apresentados na tabela 6 .

Tabela 6. Estimativas do ganho de seleção, em unidades de nota e em \%, para o caráter resistência ao NCS (raça 1) e os respectivos números de repetições utilizados, com a intensidade de seleção de $4 \%(i=-2,154)$

\begin{tabular}{lcc}
\hline \multirow{2}{*}{ Número de Repetições $(r)$} & \multicolumn{2}{c}{ Ganho de seleção } \\
\cline { 2 - 3 } & unidades de nota & $\%$ \\
\hline 3 & $-11,36$ & $-16,65$ \\
4 & $-12,58$ & $-18,44$ \\
5 & $-13,54$ & $-19,84$ \\
6 & $-14,31$ & $-20,97$ \\
7 & $-14,96$ & $-21,93$ \\
8 & $-15,50$ & $-22,72$ \\
9 & $-15,96$ & $-23,39$ \\
10 & $-16,37$ & $-23,99$ \\
\hline
\end{tabular}

De acordo com as estimativas dos ganhos de seleção, observou-se, como era de se esperar, que há aumento deste ganho quando se utiliza maior número de repetições, ou seja, há uma esperada redução na média do índice de fêmeas (NCS - raça 1) na geração seguinte. Porém, como se pode observar na tabela 6 , esse ganho é gradual e diminui com o uso de maior número de repetições. Assim, recomenda-se utilizar maior número de repetições que três, porém esse número não pode ser excessivo, ficando em torno de sete repetições. Além do maior espaço físico necessário para a avaliação em casa de vegetação, há também a dificuldade em se avaliar grande número de genótipos com maior número de repetições, uma vez que a avaliação é trabalhosa e complexa (ConCiBido et al., 2004).

Os resultados advindos dos testes de normalidade, das estimativas da herdabilidade e do número de locos segregantes indicam que a resposta ao NCS (raça 1) das linhagens revelou características de caráter quantitativo, o que condiz com relatos de Yue et al. (2001b). Os autores citados observaram em seu trabalho estimativa da herdabilidade, em população estudada para raça 1 do NCS, o valor aproximado de 0,55 , em que mencionaram ser a estimativa mais baixa quando comparada com estimativas da herdabilidade para as raças 2, 3, 5 e 14. Desse modo, para a estimativa verificada neste trabalho $\left(h_{2}=0,258\right)$ também houve baixa magnitude, além do número de locos segregantes estar em torno de 23,8 (Tabela 4).

No entanto, o número de locos segregantes para o caráter em questão foi alto, em relação a estudos anteriores. Esse resultado pode ter sido em função de se ter trabalhado com uma população pequena (176 indivíduos) e com um número baixo de repetições, além de se ter trabalhado apenas com uma geração $\left(\mathrm{F}_{6}\right)$. Além disso, observou-se que a distribuição das médias do IF das linhagens não conseguiu alcançar o genitor resistente (Hartwig) além de ter ocorrido uma variação transgressiva em relação ao genitor suscetível (EMGOPA - 316), confirmando que o número de indivíduos da população avaliada foi insuficiente em relação à variação total do caráter. Isso pode ter acarretado uma superestimativa do número de locos segregantes, o que indica necessidade de se trabalhar com maior número de indivíduos, maior número de repetições e mais gerações para o estudo da genética envolvida na resistência da soja ao NCS (raça 1).

Esses resultados confirmam os relatos de outros autores que afirmam ser o melhoramento genético da soja, visando ao desenvolvimento de cultivares resistentes ao NCS, bastante complexo, uma vez que a base genética da resistência ainda não é bem conhecida e por se tratar de uma herança que envolve a genética do hospedeiro e do patógeno.

Uma vez que os dados revelam caráter quantitativo, o trabalho de melhoristas para selecionar genótipos resistentes a essa raça do NCS torna-se mais difícil, o que indica necessidade de se trabalhar com maior número de genótipos para avaliação e seleção de indivíduos superiores.

\section{CONCLUSÕES}

1. Os resultados constantes da distribuição de normalidade das médias dos índices de fêmeas, bem como da estimativa da herdabilidade e do número de locos segregantes indicam que a resposta das linhagens ao NCS (raça 1) apresentou comportamento de caráter quantitativo, ou seja, caráter de herança poligênica. 
2. Foram observadas linhagens promissoras para o caráter em questão, porém como é de difícil avaliação, recomenda-se utilizar maior número de linhagens $\mathrm{F}_{6}$ na avaliação fenotípica e sete repetições para avaliação da reação ao NCS.

3. A necessidade de se fazer correção para efeitos macroambientais aumentou o erro das estimativas.

\section{REFERÊNCIAS}

ALZATE-MARIN, A.L.; CERVIGNIN, G.D.L.; MOREIRA, M.A.; BARROS, E.G. Seleção assistida por marcadores moleculares visando ao desenvolvimento de plantas resistentes a doenças, com ênfase em feijoeiro e soja. Fitopatologia Brasileira, Brasília, v.30, n.4, p. 33-342, 2005.

ARANTES, N.E.; KIIHL, R.A.S.; ALMEIDA, L.A. Melhoramento genético visando à resistência. In: SILVA, J.F.V. O nematóide de cisto da soja: A experiência brasileira.. Jaboticabal: SBN Sociedade Brasileira de Nematologia, 1999. p. 105-117.

CARVALHO, V. P; ABDELNOOR, R.V.; ALMEIDA, A.M.R.; ARIAS, C.A.A. Marcadores RAPD e microssatelite ligados a resistência ao nematóide de cisto da soja, Heterodera glycines Ichinohe, raça 3. Genetics and Molecular Biology, Ribeirão Preto, v.22, n.3, p.325-326, Oct.1999. (Supplement)

COCKERHAM, C. C. Modifications in estimating the number of genes for a quantitative character. Genetics, Baltimore, v.114, p. $659-664,1986$.

CONCIBIDO, V.C.; DOUGLAS, L.; DENNY, R.; ORF, J.H.; YOUNG, N.D. Genome mapping of soybean cyst nematode resistance genes in Peking, PI 90763, and PI 88788 using DNA markers. Crop Science, Madison, v.37, n.1, p.258-264, 1997.

CONCIBIDO, V.C.; DIERS, B.W.; RAO-ARELLI, P. A decade of QTL mapping for cyst nematode resistance in soybean. Crop Science, Madison, v.44, p.1121-1131, 2004.

EMBRAPA. Tecnologias de produção de soja - Paraná - 2004. Londrina: Embrapa Soja, 2003. 281p. (Sistemas de produção/ Embrapa Soja, 2003).

NOEL, G.R. History, Distribuition, and Economics. In: RIGGS, R.D.; WRATHER, J.A. Biology an management of the soybean cyst nematode. St Paul: APS Press, 1992. p.15-26.

PÍPOLO, V. C.; FERRAZ, L.C.C.B. Resistência a nematóides. In: DESTRO, D.; MONTALVÁN, R. Melhoramento genético de plantas, 1. ed. Londrina: Editora UEL, 1999. Cap.29, p.515-540.

RAO-ARELLI, A.P. Inheritance of resistance to Heterodera glycines race 3 in soybean accessions. Plant Disesase, St. Paul, v.78, p.898-900, 1994.

SCHIMITT, D.P.; SHANNON, G. Differentiating soybean responses to Heterodera glycines races. Crop Science, Madison, v.32, p. 275-277, 1992.
YORINORI, J.T., CHARCHAR, M.J.D., NASSER, L.C.B.; HENNING, A.A. Doenças da soja e seu controle. In: ARANTES, N.E.; SOUZA, P.I.M. (Eds.). Cultura de Soja nos Cerrados. Piracicaba: Potafos, 1993. p.333-397.

YUE, P.;SLEPER, D. A.; RAO-ARELLI, P. R. Mapping resistance to multiple races of Heterodera glycines in soybean PI 89772. Crop Science, Madison, v.41, p.1589-1595, 2001a.

YUE, P.; RAO-ARELLI, P. R., SLEPER, D. A. Molecular characterization of to Heterodera glycines in soybean PI 438489B. Theoretical and Applied Genetics, Berlin, v.102, p. $921-928,2001 b$.

WRATHER, J.A.; ANDERSON, T.R.; ARSYAD, D.M.; TAN, Y.; PLOPER, L.D.; PORTO-PUGLIA; RAM, H.H.; YORINORI, J.T. Soybean disease loss estimates for the top 10 soybeanproducing countries in 1998. Canadian Journal of Plant Pathology, Guelph, v.23, p.115-121, 2001. 